\title{
Comparison between S-ketamine and clonidine in caudal analgesia
}

\author{
Onesimo D. Ribeiro Jr ${ }^{1}$, Luiz Carlos de Abreu ${ }^{2}$, Vitor E. Valenti ${ }^{2,3}$, José Raul Cisternas ${ }^{2}$, Deise \\ Saletti $^{1}$, Carla J. B. Lima ${ }^{1}$, Diego N. Silvestre ${ }^{1}$, Ivan R. B. Godoy ${ }^{1}$, Luiz G. M. Mello ${ }^{1}$, Vania B. \\ Nascimento ${ }^{4}$ and Lourdes C. Martins ${ }^{1}$
}

\author{
${ }^{1}$ Disciplina de Anestesiologia, Faculdade de Medicina do ABC, Santo André, SP, Brasil. \\ ${ }^{2}$ Departamento de Morfologia e Fisiologia, Faculdade de Medicina do ABC, Santo André, SP, Brasil. \\ ${ }^{3}$ Departamento de Fonoaudiologia, Faculdade de Filosofia e Ciências, Universidade Estadual Paulista, Marília, SP, \\ Brasil. \\ ${ }^{4}$ Disciplina de Saúde Coletiva e, Faculdade de Medicina do ABC, Santo cAndré, SP, Brasil.
}

Accepted 14 November, 2011

\begin{abstract}
We aimed to compare the analgesic efficacy of the caudal administration of a combination of preservative free S-ketamine or clonidine with bupivacaine in children. The study included 51 children aged between 3 and 8 years old and physical status between I and II according to: American Society of Anesthesiologist. They were randomly divided into three groups: Group B - bupivacaine $0.25 \%, 0.75$ $\mathrm{ml} / \mathrm{kg}$ without adrenaline; Group C - bupivacaine $0.25 \%, 0.75 \mathrm{ml} / \mathrm{kg}$ without adrenaline and clonidine 1 $\mu \mathrm{g} / \mathrm{kg}$ and; Group K - bupivacaine $0.25 \%, 0.75 \mathrm{ml} / \mathrm{kg}$ without adrenaline and S-ketamine $0.5 \mathrm{mg} / \mathrm{kg}$ without conservative. In this study, medication was not used before anesthesia. The evaluation of postoperative analgesia was accomplished through the pain scale of Ouch, the motor blockade assessed by modified Bromage scale and the level of sedation through the three-point scale. The combination of caudal S-ketamine and clonidine with bupivacaine prolonged the duration of postoperative analgesia $(p<0.05)$ compared to bupivacaine alone. Regarding hemodynamic parameters, bupivacaine associated with clonidine $(\mathrm{C})$ and bupivacaine associated with S-ketamine (K) groups presented diastolic blood pressure changes in the postoperative period. Respiratory rate, regardless of group, showed significant differences over time $(p<0.05)$. The studied groups showed non significant changes in the degree of motor blockade and sedation score and we observed no clinical significant side effects. S-ketamine and clonidine associated with bupivacaine prolongs postoperative analgesia without clinically significant side effects.
\end{abstract}

Key words: Pediatric assistants, anesthesia, analgesia, epidural, anesthesia, caudal, anesthetics.

\section{INTRODUCTION}

Analgesia may reduce postoperative complications and speed recovery when well done (Montané et al., 2010; Parhizkar et al., 2011; Canbek et al., 2011; Ping et al., 2011). It allows for early ambulation and motion and facilitates the exchange of dressings and bowel motility,

${ }^{*}$ Corresponding author. E-mail: cdh.fsp@gmail.com. Tel: (55) 11 5493-4993.

Abbreviations: BIH, Bilateral inguinal herniorrhaphy; RIH, right inguinal hernia; LIH, Left inguinal hernia; PCP, phencyclidine. leading patients to quickly take their daily routine activeities (Barbosa and Guinsburg, 2003; Lee and Sanders, 2000). Besides pain relief (Abbas et al., 2011; Woode et al., 2011), post-operative analgesia should be achieved with the least collateral damage, such as hypertension, nausea, vomiting, pruritus, respiratory depression and sedation (Barbosa and Guinsburg, 2003).

Caudal analgesia is used to prolong the postoperative analgesia in pediatric ambulatory surgery when it is located below the umbilicus. This technique of regional anesthesia is favored for its safety performance and wide acceptance by physicians (Dalens and Hasnaoui, 1989; 
Makkar and Wig, 2011). It reduces the use of anesthetics used for general anesthesia, such as inhaled gases and intravenous drugs, hence, providing adequate analgesia in both intraoperative and postoperative period (Klimscha et al., 1998). However, if the caudal analgesia is used without other adjuvant drugs to local anesthetics, most patients require supplementation of analgesia, usually done through oral analgesic medication, approximately four to six hours after surgery (Weber and Wulf, 2003).

Local anesthetics belong to the aminoamides group, that is, bupivacaine and ropivacaine, and are used in the caudal analgesia (Berde, 1993; Mazoit et al., 1988). Some drugs have been associated with local anesthetics in order to prolong analgesia in the postoperative period, such as S-ketamine and clonidine. The preservative free $\mathrm{S}$-ketamine is used in caudal analgesia as a NMDA (Nmethyl D-aspartate) antagonist with the elimination of the possibility of neurotoxic effects (De Negri et al., 2011). Clonidine, an alpha-2 adrenergic agonist, prolongs the duration of postoperative analgesia when it is combined with local anesthetics (Ivani et al., 2000) through its inhibition of the transmission of nociceptive stimuli in the dorsal horn of the spinal cord. It is considered a safe drug (Lee and Rubin, 1994; Johnston et al., 1999).

De Negri et al. (2001) have already investigated the association of S-ketamine and clonidine with ropivacaine. In addition, bupivacaine has been the most frequently used local anesthetic in our Institution. Therefore, we endeavored to compare the combination of S-ketamine with the local anesthetic bupivacaine and the association of clonidine with bupivacaine without adrenaline in children that underwent caudal analgesia.

\section{METHODS}

\section{Population}

This study was conducted in the State Hospital in Santo Andre SP, after obtaining of the approval of the Ethics Committee in Research of the authors' Institution and a signed informed consent from the parents or guardians. We included 51 children aged from 2 to 8 years old, American Society of Anesthesiologist (ASA) physical status Classes I to II who were scheduled for elective inguinal hernia repair, orchidopexy and circumcision. We excluded children with mental disabilities, neuromuscular or other neurologic diseases, spinal abnormalities, history of allergy to local anesthetics, use of anticoagulant and antiplatelet drugs, organ transplantation, cancer history and major surgery planned in the next year.

The selected children were randomly signed into three groups: Group B - bupivacaine $0.25 \%, 0.75 \mathrm{ml} / \mathrm{kg}$ without adrenaline; Group C - bupivacaine $0.25 \%, 0.75 \mathrm{ml} / \mathrm{kg}$ without adrenaline and clonidine $1 \mu \mathrm{g} / \mathrm{kg}$, and Group K - bupivacaine $0.25 \%, 0.75 \mathrm{ml} / \mathrm{kg}$ without adrenaline and S-ketamine $0.5 \mathrm{mg} / \mathrm{kg}$ without conservative. No premedication was given before surgery. The placebo group was investigated because there are some studies in the literature which showed the superiority of analgesic effects of the caudal combination of bupivacaine and clonidine or S-ketamine compared with bupivacaine alone (Marhofer et al., 2000; Joshi et al., 2004). Also, we used $1 \mathrm{ug} / \mathrm{kg}$ of clonidine instead of $2 \mathrm{ug} / \mathrm{kg}$ in order to investigate a new dose of this compound (Joshi et al., 2004).

\section{Anesthetic induction}

General anesthesia was induced with a face mask with sevoflurane $6 \%$ combined with $100 \%$ of oxygen. After the caudal analgesia maintenance sevoflurane was changed to $3 \%, \mathrm{O}_{2}$ to $50 \%$ and $\mathrm{N}_{2} \mathrm{O}$ to $50 \%$. The children remained in spontaneous respiration with a face mask (Baraka in the system of Jackson-Rees). After induction of general anesthesia, saline $0.9 \%$ was infused through a venous catheter $(10 \mathrm{ml} / \mathrm{kg} / \mathrm{h})$. By reaching the sedation level, the child was placed at lateral position and the puncture needle of the sacral hiatus with $30 \times 8$ in aseptic conditions was performed. At the end of the caudal analgesia, the children were placed at the supine position.

\section{Variables}

Heart rate, blood pressure and arterial oxygen saturation were recorded before anesthetic induction, immediately after induction, after performing caudal analgesia and every 5 min during surgery. Hemodynamic parameters also included blood pressure measurement (systolic $<60 \mathrm{mmHg}$ - hypotension), heart rate $(<80$ beats per minute - bradycardia) and respiratory rate $(<12$ breaths per minute respiratory depression).

\section{Postoperative recovery}

At the end of the surgery, the children were referred to postanesthesia recovery and heart rate, blood pressure, arterial oxygen saturation, assessment of analgesia, evaluation of motor block and sedation level were recorded every $15 \mathrm{~min}$ for a period of $6 \mathrm{~h}$. If the child presented pain intravenous (i.v.) dipyrone $(30 \mathrm{mg} / \mathrm{kg}$ ) was administrated. In the case of nausea and vomiting, we used i.v. ondansetron hydrochloride $(0.15 \mathrm{mg} / \mathrm{kg})$.

The evaluation of postoperative analgesia was accomplished through the Oucher pain scale (Johnston and Wells, 1989; Ozcengiz et al., 1998), which is based on the child's expression (0 to 20: happy, 20 to 40 : quiet; 40 to 60 : tense/ready to cry; 60 to 80 : upset/crying; 80 to 100: crying/crying with tears). Motor block was assessed by modified Bromage scale (Turner et al., 1996) $(0=$ no residual block; $1=$ unable to raise extended legs; $2=$ unable to flex knees; $3=$ unable to flex the ankles). The parents were instructed about the use of pain scoring system during the preoperative visit.

The assessment of sedation level was achieved by three-point scale, ranging from awaken patients to asleep patients without response to verbal command ( $0=$ awake; $1=$ asleep but responds to verbal commands; 2 = sleeping and not respond to verbal command) (Doyle et al., 1993). The patient was evaluated in the post-anesthesia recovery by an anesthesiologist who did not participate in the surgery. From the hospital discharge, around six hours after the surgery, a doctor who did not participate in the surgery and post-anesthesia recovery made telephone contact with parents or guardians of the children to assess the need for analgesic medication and the occurrence of side effects.

\section{Statistical analysis}

Variance homogeneity and the adherence to the normal curve were verified by Levene and Kolmogorov-Smirnov tests, respectively. Considering that the both variables were positive, we applied one way ANOVA for repeated measures to compare values in the same group and we applied one way ANOVA to verify differences between the groups followed by the Tukey post test (HSD - Turkey - honest significant differences). Differences were considered significant when the probability of a Type I error was less than $5 \%$ $(p<0.05)$. We used Statistica 6.0 and SPSS 14.0 for Windows. 
Table 1. Data regarding demographic profile, ASA, hemodynamic and respiratory determinants at the preoperative period.

\begin{tabular}{lccc}
\hline Variable & Group B $(\mathbf{n}=\mathbf{1 0})$ & Group C $(\mathbf{n}=\mathbf{2 1})$ & Group K $(\mathbf{n}=\mathbf{2 0})$ \\
\hline Age (years) & $3.9 \pm 1.5$ & $5 \pm 1.5$ & $4.6 \pm 1.7$ \\
Weight $(\mathrm{kg})$ & $16.7 \pm 4.7$ & $19.8 \pm 4.1$ & $17.9 \pm 3.8$ \\
ASA & $\mathrm{I}$ & $\mathrm{I}$ & $\mathrm{I}$ \\
$\mathrm{SAP}(\mathrm{mmHg})$ & $95.9 \pm 14$ & $107 \pm 17.7$ & $101.6 \pm 16.7$ \\
$\mathrm{DAP}(\mathrm{mmHg})$ & $50.7 \pm 11.4$ & $59.7 \pm 14.2$ & $53.4 \pm 15.5$ \\
$\mathrm{HR}(\mathrm{bpm})$ & $99.4 \pm 19.7$ & $103.5 \pm 19.1$ & $105 \pm 11.5$ \\
$\mathrm{RR}(\mathrm{ipm})$ & $27.8 \pm 8.2$ & $24.5 \pm 8$ & $30.5 \pm 6.8$ \\
$\mathrm{SO}_{2}(\%)$ & $88.4 \pm 30.7$ & $65.8 \pm 46.9$ & $63.9 \pm 47.4$ \\
\hline
\end{tabular}

ASA, American Society of Anesthesiologist: SAP, baseline systolic arterial pressure; DAP, diastolic arterial pressure; $\mathrm{HR}$ : heart rate; $\mathrm{RR}$, respiratory rate; $\mathrm{SO}_{2}$, arterial oxygen saturation.

Table 2. Distribution (n) of surgical procedures in the three groups.

\begin{tabular}{lccc}
\hline Surgical procedure & Group B & Group C & Group K \\
\hline BIH & $2(20 \%)$ & $4(19 \%)$ & $4(20 \%)$ \\
Circumcision & $8(80 \%)$ & $15(71.4 \%)$ & $13(65 \%)$ \\
Circumcision and BIH & & $1(4.8 \%)$ & $1(5 \%)$ \\
Circumcision and RIH & & $1(4.8 \%)$ & $1(5 \%)$ \\
Circumcision and LIH & & & $1(5 \%)$ \\
\hline
\end{tabular}

$\mathrm{BIH}$, Bilateral inguinal herniorrhaphy; RIH, right Inguinal herniorrhaphy; $\mathrm{LIH}$, left inguinal herniorrhaphy.

Table 3. Duration (hours) of post-operative analgesia, time from caudal injection.

\begin{tabular}{cc}
\hline Group & Time $(\mathbf{h})$ \\
\hline B & $7 \pm 0.8$ \\
C & $19 \pm 0.7^{\star}$ \\
K & $18 \pm 0.8^{*}$ \\
\hline
\end{tabular}

${ }^{*} p<0.001$ : compared with Group B.

\section{RESULTS}

The study involved 51 children, divided into three groups. The patient's characteristics are described in Table 1. The three groups were similar with regard to age, physical status, baseline systolic and diastolic arterial pressure, heart rate, respiratory rate and arterial oxygen saturation values in the preoperative period. In the intraoperative period hemodynamic and respiratory patterns were no significant differences among groups.

According to Table 1, we observe children that participated in Group B, which underwent bilateral inguinal herniorrhaphy $(\mathrm{BIH})$ and circumcision. Group $\mathrm{C}$ was composed of 21 children between 2 and 8 years old who underwent $\mathrm{BIH}$, circumcision, circumcision and $\mathrm{BIH}$ and right inguinal hernia $(\mathrm{RIH}) .20$ children aged 2 to 8 years old participated in the Group K, they were submitted to $\mathrm{BIH}$, circumcision, $\mathrm{BIH}$ and circumcision, circumcision and $\mathrm{RIH}$ and left inguinal hernia (LIH) (Table 2).

The duration of postoperative analgesia was significantly longer in S-ketamine /bupivacaine and clonidine /bupivacaine groups compared to bupivacaine alone (Table 3).

In relation to hemodynamic parameters, we observed that only the diastolic blood pressure in the postoperative period was significant different between the three groups (Table 4). With regard to respiratory rate, there were no differences between the three groups, however, we noted differences over time $(p<0.05)$ (Table 5).

Regarding side effects, no cases of nausea and vomiting in the $\mathrm{K}$ and $\mathrm{C}$ groups was observed. We observed cases of nausea in the bupivacaine group. 
Table 4. Diastolic arterial pressure after surgery.

\begin{tabular}{cccc}
\hline Time (Min) & Group B & Groups C & Group K \\
\hline 30 & $49.9 \pm 16.2$ & $64.9 \pm 15.1^{*}$ & $63.9 \pm 15.2^{*}$ \\
60 & $517 \pm 14$ & $66 \pm 13.4^{*}$ & $64.6 \pm 10.8^{*}$ \\
90 & $52 \pm 11.4$ & $63.4 \pm 15.2^{*}$ & $59.7 \pm 11.4$ \\
120 & $51 \pm 7.6$ & $63.9 \pm 10^{*}$ & $58.6 \pm 10.9$ \\
160 & $53 \pm 7.4$ & $61.2 \pm 8.4^{*}$ & $57.4 \pm 9.7$ \\
180 & $51.6 \pm 6.5$ & $61 \pm 10.6^{*}$ & $54.7 \pm 10.4$ \\
\hline
\end{tabular}

${ }^{*} \mathrm{p}<0.05$ : Compared with Group B.

Table 5. Respiratory rate at pre and postoperative periods.

\begin{tabular}{cccc}
\hline Time (min) & Group B & Groups C & Group K \\
\hline 0 (preoperative) & $27.8 \pm 8.2$ & $24.5 \pm 8$ & $30.5 \pm 6.8$ \\
10 & $33.5 \pm 3.9^{*}$ & $26.5 \pm 6.7$ & $32.9 \pm 9.7^{*}$ \\
20 & $33.1 \pm 3.1^{*}$ & $28.6 \pm 7.5$ & $32.6 \pm 9$ \\
30 & $31.7 \pm 4.1$ & $29 \pm 5.8^{*}$ & $32.6 \pm 9$ \\
40 & $27.7 \pm 4.2$ & $28.6 \pm 6.9$ & $32.9 \pm 8.9^{*}$ \\
50 & $29 \pm 5.1$ & $26.8 \pm 6$ & $32.4 \pm 10.7$ \\
\hline
\end{tabular}

${ }^{*} p<0.05$ : Different of $0 \mathrm{~min}$ in the same group.

Table 6. Incidence of side-effects.

\begin{tabular}{llll}
\hline Side-effect & Group B & Group C & Group K \\
\hline Residual motor block & 0 & 0 & 0 \\
Sedation & 0 & 0 & 0 \\
Respiratory depression & 0 & 0 & 0 \\
Nauseas & $1(10 \%)$ & 0 & 0 \\
Hallucination & & $1(4.8 \%)$ & $2(10 \%)$ \\
Vomiting & 0 & 0 & 0 \\
Nystagmus & 0 & 0 & 0 \\
Odd behaviour & 0 & 0 & 0 \\
Urinary retention & 0 & 0 & $1(10 \%)$ \\
Paraesthesia & 0 & 0 & 0 \\
Lumbar pain & 0 & 0 & 0 \\
Agitation & 0 & 0 & $5(5 \%)$ \\
\hline
\end{tabular}

$\mathrm{BIH}$, Bilateral inguinal herniorrhaphy; $\mathrm{RIH}$, right inguinal herniorrhaphy; $\mathrm{LIH}$, left inguinal herniorrhaphy.

Hallucination was identified in $\mathrm{C}$ and $\mathrm{K}$ groups. There were cases of urinary retention and agitation in Group K. No patient was discharged delayed due to longer motor blockade or excessive sedation. All children were back to their residence over a period of approximately seven $h$ (Table 6).

\section{DISCUSSION}

As main findings, there were no significant differences among the three groups (ketamine plus bupivacaine vs. clonidine plus bupivacaine vs. bupivcaine alone) regarding age, weight and duration of surgery. Similarly, systolic arterial pressure, heart rate, respiratory rate and arterial oxygen saturation showed no significant differences between groups; we observed only reduced values of diastolic arterial pressure in the $\mathrm{K}$ and $\mathrm{C}$ groups after surgery. Our findings indicate that S-ketamine and clonidine enhance the effects of bupivacaine in terms of duration of postoperative analgesia.

In the postoperative period, regarding the hemodynamic 
profile of the groups, only diastolic blood pressure decreased in the groups anesthetized with S-ketamine and clonidine associated with bupivacaine. However, Choudhuri et al. (2008) combined ketamine with bipuvacaine and did not observe hypotension or bradycardia during and after surgery. In our study, we used S-ketamine; the pharmacokinetic properties of Sketamine are generally comparable with the racemic mixture. S-ketamine is approximately two times as potent as racemic ketamine (Adams and Werner, 1997). The analgesic potency of the two enantiomers depends on their relative affinity for phencyclidine (PCP) binding sites (associated with the NMDA receptor) (Zeilhofer et al., 1992). We believe this explains the difference between their results and our findings. In relation to clonidine, a previous study support our data, because it was found that for the first three hours postoperatively, children receiving caudal clonidine presented lower blood pressure as compared to children with caudal bupivacaine alone (Motsch et al., 1997). On the other hand, Klamt et al. (2003) found no changes in diastolic arterial pressure when epidural infusion of clonidine or clonidine plus ropivacaine was done. The changes in diastolic arterial pressure observed in our study associated with epidural clonidine and ketamine administration is most likely explained by two interacting mechanisms. First, systemic uptake of clonidine and ketamine from the epidural space into the systemic circulation will cause secondary interactions with centers in the brain stem (that is, locus coeruleus, rostroventrolateral medulla, nucleus ambiguous and the nucleus of the solitary tract) that affect neural regulation of the cardiovascular system (Valenti et al., 2009a; Valenti et al., 2009b; Cisternas et al., 2010). Second, epidural clonidine and ketamine in the dose used by us is associated with improved postoperative pain relief (De Negri et al., 2001). A reduced nociceptive input is likely to result in reduced blood pressure variability due to a reduction of the paingenerated stress response.

According to our data, the respiratory rate was different in relation to time in the three groups, it increased after caudal ketamine and clonidine associated with bupivacaine and after caudal bupivacaine alone. Nevertheless, the literature contradicts our results, because De Negri et al (2001) found no respiratory alterations for both ketamine and clonidine associated to ropivacaine. Sedation with caudal clonidine and bupivacaine did not affect respiration (Motsh et al., 1997). Furthermore, epidural infusion of clonidine alone or clonidine plus ropivacaine did not change respiratory rate and arterial oxygen saturation (Klamt et al., 2003). Taken together, although we found a small degree of respiratory depression, we believe that the association of caudal ketamine and clonidine with bupivacaine tends to cause respiratory depression without clinical relevance.

Our study demonstrated a prolonged period in which it would be required the introduction of analgesics after surgery in both S-ketamine and clonidine groups as compared to bupivacaine group. The postoperative sedation and prolonged motor block was not observed in S-ketamine and clonidine groups. A few patients presented side effects such as hallucinations during the time they were in the post-anesthesia recovery. Caudal anesthesia may result in certain disorders associated with urination, such as urinary retention and urinary incontinence (Zeihofer et al., 1992; Motsh et al., 1997). In this study, an insignificant number of cases of urinary retention was detected in the group which bupivacaine was associated with S-ketamine. At $6 \mathrm{~h}$, when the children remained in hospital until being discharged to home, a small number of patients presented nausea in the bupivacaine group and no cases of vomiting was observed in the three groups (De Negri et al., 2001).

Several authors stated that caudal analgesia promotes the reduction of postoperative pain that can get 4 to $7 \mathrm{~h}$ of analgesia (Lauretti et al., 2005; Akbas et al., 2005). Our investigation demonstrated that S-ketamine associated with bupivacaine determined a period of postoperative analgesia similar to that found in previous studies (Lauretti et al., 2005; Akbas et al., 2005). Clonidine combined with bupivacaine showed an increase in duration and good quality of the blockade, findings that are supported by previous researches (Lauretti et al., 2005; Akbas et al., 2005).

Patients who received clonidine combined with bupivacaine presented absence of sedation, similar to patients receiving S-ketamine plus bupivacaine or bupivacaine alone. A previous study compared the benefits of epidural S-ketamine and clonidine in adult orthopedic surgery. Sensory level to pinprick, sedation, surgical and anesthetic time and visual analog scale scores for pain at first rescue medication were similar among the groups (Laureti et al., 2005). Nonetheless, De Negri et al. (2001) found 2 cases of sedation in the group which clonidine was combined with rupivacaine and 2 cases in the group which S-ketamine was combined with rupivacaine. Akbar et al. (2005) found no sedation score differences between rupivacaine alone group and rupivacaine associated with ketamine group, however, sedation scores were higher in the rupivacaine plus clonidine group for the first one hour period after the operation than the other groups. Opioid-receptors activation in the central nervous system is associated with sedation. Koppert et al. (2003) investigated the time course of analgesic and hyperalgesic effects of the mureceptor agonist remifentanil alone or in combination with S-ketamine or clonidine. They suggested different mechanisms: (1) Opioid-induced post infusion hyperalgesia could be abolished by S-ketamine, suggesting an N-methyl-d-aspartate-receptor mechanism; (2) Conversely, elevated pain ratings after opioid infusion were not reduced by ketamine but were alleviated by clonidine, suggesting an alpha(2)-receptor mechanism. This is a possible explanation for the findings of previous 
investigations (De Negri et al., 2001; Koppert et al., 2003).

Our study presents some points that should be addressed: The number of children evaluated is small, however, statistical tests revealed significance. We did not assess total analgesic requirement over the first $24 \mathrm{~h}$ after surgery. On the other hand, there was no complaining of the children's parents or guardians regarding any damage effect on the children and the children did not come back to the hospital due to pain complications. Previous studies indicated the superiority of analgesic effects of the caudal combination of bupivacaine and clonidine or S-ketamine compared with bupivacaine alone (Joshi et al., 2004; Makkar and Wig, 2011). We investigated a placebo group.

The present study was not designed in a blinded or double-blinded fashion which makes it too difficult to exclude the bias of the assessors.

Although a very similar study was previously conducted, our study investigated a new dosage of the anesthetic, which provide new and relevant elements to the literature. As a main finding, our study investigated a new dosage of the anesthetic, which add new elements to the literature and suggest further procedures to the clinical practice.

In conclusion, S-ketamine associated with bupivacaine and clonidine associated with bupivacaine prolongs postoperative analgesia compared to bupivacaine aloneand presents no side effects. The need for analgesic drugs is reduced. We indicate that S-ketamine and clonidine can be safely used as adjuvant in the caudal analgesia in pediatric surgery.

\section{ACKNOWLEDGEMENTS}

This study received financial support from Núcleo de Estudos, Pesquisas e Assessoria à Saúde da Faculdade de Medicina do ABC (NEPAS-FMABC) and Fundação de amparo à Pesquisa do Estado de São Paulo (FAPESP).

\section{REFERENCES}

Abbas M, Subhan F, Mohani N, Rauf K, Ali G, Khan M (2011). The involvement of opioidergic mechanisms in the activity of Bacopa monnieriextract and its toxicological studies. Afr. J. Pharm. Pharmacol., 5: 1120-1124.

Adams HA, Werner C (1997). From the racemate to the eutomer: (S)ketamine. Renaissance of a substance? Anaesthetist, 46: 34-40.

Akbas M, Titiz TA, Ertugrul F (2005). Comparison of the effect of ketamine added to bupivacaine and ropivacaine, on stress hormone levels and duration of caudal analgesia. Acta Anaesthesiol. Scand., 49: 1520-1526.

Barbosa SMM, Guinsburg R (2003). Pain according to pediatric age. Curitiba.

Berde CB (1993). Toxicity of local anesthetics in infants and children. J Pediatr., 122: S14-S20.

Canbek M, Ustüner MC, Kabay S, Uysal O, Ozden H, Bayramoğlu G, Sentürk H, Ozbayar C, Bayramoglu A, Ustüner D, Degirmenci I (2011). The effect of gallic acid on kidney and liver after experimental renal ischemia/reperfusion injury in the rats. Afr. J. Pharm. Pharmacol., 5: $1027-1033$

Choudhuri AH, Dharmani P, Kumarl N, Prakash A (2008). Comparison of caudal epidural bupivacaine with bupivacaine plus tramadol and bupivacaine plus ketamine for postoperative analgesia in children. Anaesth. Intensive Care, 36: 174-179.

Cisternas JR, Valenti VE, Alves TB, Ferreira C, Petenusso M, Breda JR, Pires AC, Tassi N, de Abreu LC (2010). Cardiac baroreflex is already blunted in eight weeks old spontaneously hypertensive rats. Int. Arch. Med., 3: 2.

Dalens B, Hasnaoui A (1989). Caudal anesthesia in pediatric surgery: success rate and adverse effects in 750 consecutive patients. Anesth. Analg., 68: 83-89.

De Negri P, Ivani G, Visconti C, De Vivo P (2001). How to prolong postoperative analgesia after caudal anestesia with ropivacaine in children: S-Ketamine versus clonidine. Pediatr. Anaesth., 11: 679683.

Doyle E, Harper I, Morton NS (1993). Pacient controlled analgesia with low dose background infusion after lower abdominal surgery in children. Br. J. Anaesth., 71: 818-822.

Ivani G, De Negri P, Conio A, Amati M, Roero S, Giannone S, Lönnqvist PA (2000). Ropivacaine- clonidine combination for caudal blockade in children. Acta. Anaesth. Scand., 44: 446-449.

Johnston BE, Wells N (1989). The assessment of pain in children. Pediatr. Clin. North Am., 36: 837-54.

Johnston P, Findlow D, Aldridge LM, Doyle E (1999). The effect ketamine on $0,25 \%$ and $0,125 \%$ bupivacaine for caudal epidural blockade in children. Paediatr. Anaesth., 9: 31-34.

Joshi W, Connelly NR, Freeman K, Reuben SS (2004). Analgesic effect of clonidine added to bupivacaine $0.125 \%$ in paediatric caudal blockade. Paediatr. Anaesth., 14: 483-486.

Klamt JG, Garcia LV, Stocche RM, Meinberg AC (2003). Epidural infusion of clonidine or clonidine plus ropivacaine for postoperative analgesia in children undergoing major abdominal surgery. J. Clin. Anesth., 15: 510-4.

Klimscha W, Chiari A, Michalek-Sauberer A, Wildling E, Lerche A, Lorber C, Brinkmann H, Semsroth M (1998). The efficacy and safety of a clonidine/bupivacaine combination in caudal blockade for pediatric hernia repair. Anesth. Analg., 86: 54-61.

Koppert W, Sittl R, Scheuber K, Alsheimer M, Schmelz M, Schüttler J (2003). Differential modulation of remifentanil-induced analgesia and postinfusion hyperalgesia by S-ketamine and clonidine in humans. Anesthesiology, 99: 152-159.

Lauretti GR, Rodrigues AM, Paccola CA, Mattos AL (2005). The combination of epidural clonidine and $\mathrm{S}(+)$-ketamine did not enhance analgesic efficacy beyond that for each individual drug in adult orthopedic surgery. J. Clin. Anesth., 17: 79-84.

Lee HM, Sanders GM (2000). Caudal ropivacaine and ketamine for postoperative analgesia in children. Anaesth., 55: 798-810.

Lee JJ, Rubin AP (1994). Comparison of a bupivacaine clonidine mixture with plain bupivacaine for caudal analgesia in children. Br. J. Anaesth. 72: 258-262.

Makkar JK, Wig J (2011). Minimum local analgesic concentration of ropivacaine for intra-operative caudal analgesia in pre-school and school age children--analysis using the Dixon method. Anaesth., 66: 227-228.

Marhofer P, Krenn CG, Plöchl W, Wallner T, Glaser C, Koinig H, Fleischmann E, Höchtl A, Semsroth M (2000). S(+)-ketamine for caudal block in paediatric anaesthesia. Br. J. Anaesth., 84: 341-345.

Mazoit JX, Denson DD, Samii K (1988). Pharmacokinetcs of bupivacaine following caudal anesthesia in infants. Anesthesiology, 68: 387-391.

Montané E, Vallano A, Vidal X, Aguilera C, Laporte JR (2010). Reporting randomised clinical trials of analgesics after traumatic or orthopaedic surgery is inadequate: a systematic review. BMC Clin. Pharmacol., 10:2

Motsch J, Böttiger BW, Bach A, Böhrer H, Skoberne T, Martin E (1997) Caudal clonidine and bupivacaine for combined epidural and general anesthesia in children. Acta. Anesthesiol. Scand., 41:877-883.

Ozcengiz D, Ozbek H, Unlügenç $H$ (1998). Comparison of caudal bupivacaine for postoperative pain in children. Turk Anesteziyoloji ve Reanimasyon, 26: 39-42. 
Parhizkar S, Latiff LA, Rahman SA, Dollah MA (2011). Evaluation of estrogen-like activity of Nigella sativa in ovariectomized rats. Afr. J. Pharmacy Pharmacol., 5: 1765-1772.

Ping Z, Jiao W, Zhong Z (2011). Sevoflurane pretreatment prevents lipopolysaccharide (LPS)-induced acute lung injury in rats through up-regulated heme oxygenase-1 (HO-1) Expression. Afr. J. Pharmacy Pharmacol., 5: 1006-1011.

Turner G, Blake D, Buckland M (1996). Continuous extradural infusion of ropivacaine for prevention of postoperative pain after major orthopaedic surgery. Br. J. Anaesth., 76: 606-610.

Valenti VE, Ferreira C, Meneghini A, Ferreira M, Murad N, Ferreira Filho C, Correa JA, Abreu LC, Colombari E (2009a). Evaluation of baroreflex function in young spontaneously hypertensive rats. Arq Bras Cardiol., 92: 205-215.
Valenti VE, Imaizumi C, de Abreu LC, Colombari E, Sato MA, Ferreira C (2009b). Intra-strain variations of baroreflex sensitivity in young Wistar-Kyoto rats. Clin. Invest Med., 32: E251.

Weber $\mathrm{F}$, Wulf $\mathrm{H}$ (2003). Caudal bupivacaine and $\mathrm{s}(+)-$ ketamine for postoperative analgesia in children. Paediatr. Anaesth., 13: 244-248.

Woode E, Alagpulinsa DA, Abotsi WKM (2011). Anti-nociceptive, anxiolytic and anticonvulsant effects of an aqueous leaf extract of Leea guineensis G. Don (Family: Leeaceae). Afr. J. Pharm. Pharmacol., 5: 1132-1144.

Zeilhofer HU, Swandulla D, Geisslinger G, Brune K (1992). Differential effects of ketamine enantiomers on NMDA receptor currents in cultured neurons. Eur. J. Pharmacol., 213:155-158. 